\title{
Diffusion-weighted imaging and diffusion-weighted whole-body imaging with background body signal suppression for characterizing esophageal cancer:
}

\section{a case report}

\author{
Minoru Tomizawa' \\ Fuminobu Shinozaki \\ Aika Ozaki² \\ Akira Baba ${ }^{2}$ \\ Yoshiya Fukamizu² \\ Futoshi Matsunaga ${ }^{2}$ \\ Takao Sugiyama ${ }^{3}$ \\ Shigenori Yamamoto ${ }^{4}$ \\ Makoto Sueishi ${ }^{3}$ \\ Takanobu Yoshida ${ }^{5}$ \\ 'Department of Gastroenterology, \\ 2Department of Radiology, \\ ${ }^{3}$ Department of Rheumatology, \\ ${ }^{4}$ Department of Pediatrics, \\ ${ }^{5}$ Department of Internal Medicine, \\ National Hospital Organization \\ Shimoshizu Hospital, Yotsukaido \\ City, Japan
}

\author{
This article was published in the following Dove Press journal: \\ International Medical Case Reports Journal \\ 29 November 2013 \\ Number of times this article has been viewed
}

Purpose: Information on the extent or structure of esophageal cancer (ESC) is necessary for identifying whether the carcinoma is localized or resectable. Diffusion-weighted imaging (DWI) and diffusion-weighted whole-body imaging with background body signal suppression (DWIBS) are useful for this purpose.

Patients and methods: One case of ESC with dysphagia presented at our hospital. Endoscopic examination revealed an elevated lesion with an ulcer, and stenosis was detected. DWI showed a high-intensity signal extending from the proximal to the distal ends of the carcinoma and extending to the tunica adventitia. A strong signal was also observed using ${ }^{18} \mathrm{~F}$-fluorodeoxyglucose positron emission tomography (FDG-PET). DWIBS clearly revealed ESC, and these findings, along with those from DWI, suggested that our case had stage-T3 ESC. FDG-PET did not reveal the detailed structure of the ESC. DWIBS, on the other hand, showed that the signal extended to the tunica adventitia and the lumen of the esophagus.

Conclusion: These findings suggest that DWI and DWIBS are useful for the detection and assessment of ESC.

Keywords: positron emission tomography, endoscopy, computed tomography, cross section, squamous cell carcinoma

\section{Introduction}

Esophageal cancer (ESC) accounts for about $10 \%$ of gastrointestinal cancers. ${ }^{1}$ Lymphatic or hematologic metastasis often occurs because the esophagus is not surrounded by a serosa; therefore, long-term survival is poor, and surgery is the only curative option for ESC. ${ }^{1}$ Information on the extent or structure of ESC is necessary to determine whether it is localized or resectable. ${ }^{2}$

ESC is diagnosed by endoscopy and biopsy. Subsequently, endoscopic ultrasonography and computed tomography (CT) are performed to assess the structure of the primary lesion and the extent of invasion of surrounding tissues, as well as distant metastasis. ${ }^{318} \mathrm{~F}$-fluorodeoxyglucose positron emission tomography (FDG-PET) is useful for diagnosing cancers and differentiating them from benign lesions. Endoscopic ultrasonography is useful for differentiating stage-T1 cancer from stages T2, T3, and $\mathrm{T} 4$, but is not applicable for patients with stenosis due to ESC; such patients need to be assessed using other modalities. CT is used to evaluate lymph-nodes and distant metastasis, rather than local extension. ${ }^{4}$ It is difficult to differentiate ESC from surrounding tissues, such as muscle, using CT, and it is also difficult to determine the
Correspondence: Minoru Tomizawa Department of Gastroenterology, National Hospital Organization Shimoshizu Hospital, 934-5 Shikawatashi, Yotsukaido City, Chiba 284-0003, Japan Phone +8I 43422251 I

Fax +8 I 434213007

Email nihminor-cib@umin.ac.jp 
depth of invasion with FDG-PET. ${ }^{5}$ A single modality is desirable for detecting and determining the extent of ESC.

Magnetic resonance imaging is widely used, because it does not use ionizing radiation and has soft-tissue contrast and spatial resolution. Diffusion-weighted imaging (DWI) visualizes and assesses the random movement of water at the molecular level (Brownian motion), ${ }^{6}$ and uses spectral presaturation by inversion-recovery fat suppression. DWI images are acquired either during the holding of breath or with the aid of respiratory and cardiac triggering. ${ }^{7}$ DWI is useful for the detection of abdominal cancers, due to their increased cellularity. ${ }^{8}$ Diffusion-weighted whole-body imaging with background body signal suppression (DWIBS) images are acquired using multiple signal averaging, pre-pulse fat suppression, and heavy diffusion weighting during free breathing. ${ }^{9}$ Cancer images from DWIBS correlate with those obtained with FDG-PET. ${ }^{9}$ The rate of cancer detection using DWIBS is superior to that using FDG-PET. ${ }^{10}$ The imaging time required for DWIBS (approximately 20-30 minutes) is also shorter than that required for FDG-PET (3-5 hours).

\section{Case presentation}

Our study was reviewed by our institutional ethical committee and was not assigned as a clinical trial, since it was performed as part of routine clinical practice. Patient anonymity was preserved.

The case history is as follows. A 68-year-old man presented at our hospital with dysphagia, occurring for a period of 2 months. He did not have nausea or vomiting. Endoscopy revealed an elevated lesion in the thoracic esophagus (Figure 1A, D, G, J, and M). The lesion had an ulcer on its tip (arrows). The diseased esophagus was narrowed. His biopsy specimen revealed moderately differentiated squamous cell carcinoma. High-intensity signals were observed in the esophagus upon DWI (Figure 1B, E, H, K, and N). These signals corresponded to those from the endoscopy (Figure 1A, D, G, J, and M). The DWI signals continued from the proximal to the distal ends of the carcinoma. The anterior parts of the esophagus did not have high signal intensity (indicated by arrowheads in Figure 1). Thickening of the wall of the esophagus was found by contrast-enhanced CT (Figure 1C, F, I, L, and O). The esophageal wall showed all-around thickening. The thickness of the esophageal wall was obvious on contrastenhanced CT, but the cancer itself was not clear. However, a high-intensity signal from the ESC was seen on the DWI. The high-intensity signal extended to the tunica adventitia but not to the mediastinal structures. The patient was,

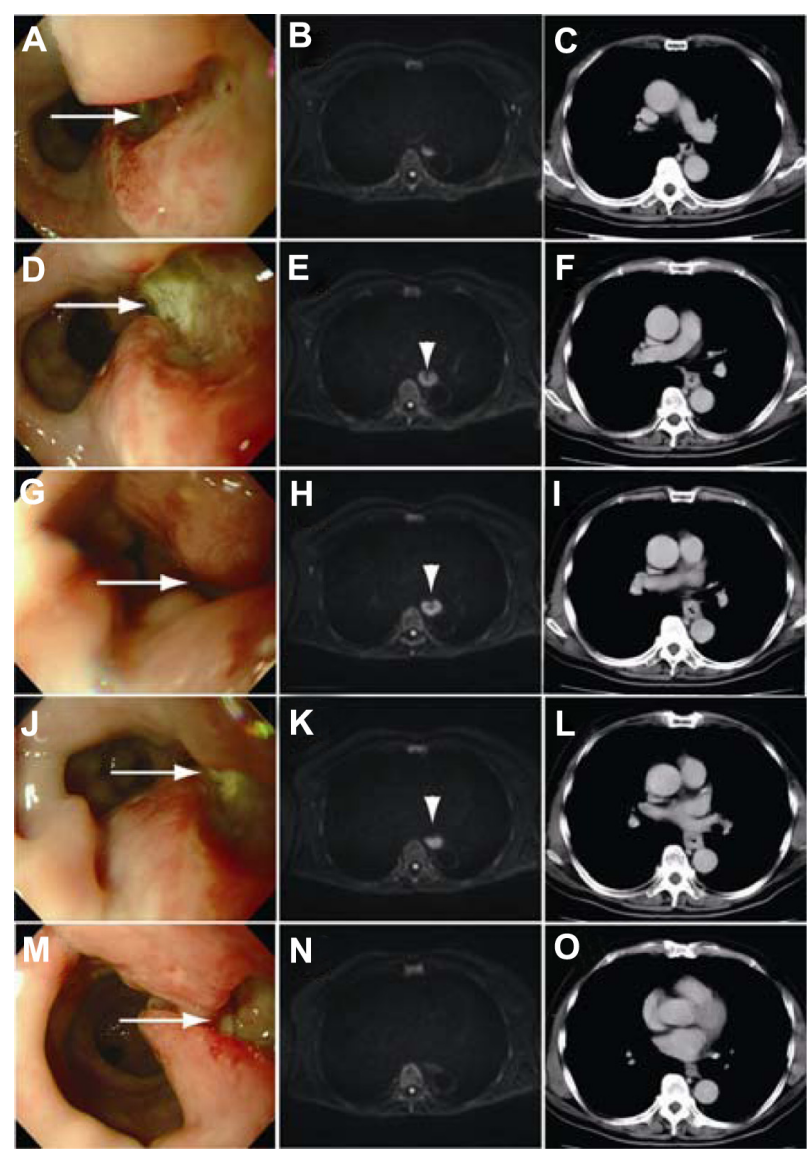

Figure I Esophageal cancer. The esophageal cancer in our case is illustrated from the proximal $(\mathbf{A}-\mathbf{C})$ to the distal $(\mathbf{M}-\mathbf{O})$ ends. (A, D, $\mathbf{G}, \mathbf{J}$, and $\mathbf{M})$ : endoscopy; $(\mathbf{B}, \mathbf{E}, \mathbf{H}, \mathbf{K}$, and $\mathbf{N})$ : diffusion-weighted magnetic resonance imaging; $(\mathbf{C}, \mathbf{F}, \mathbf{I}$, $\mathbf{L}$, and $\mathbf{O}$ ): contrast-enhanced computed tomography.

Notes: Arrow: an ulcer in the esophageal carcinoma; arrowhead: ulcer of the cancer corresponding to arrow.

therefore, diagnosed with stage-T3 ESC. The ulcer in the ESC identified by endoscopy corresponded to the depressed lesion seen with DWI.

A longitudinal space suggestive of a lumen was seen in the center of the esophagus on the cross-sectional DWI image (Figure 2A). A strong signal was also observed on the crosssectional image from the PET scan (Figure 2B). DWIBS demonstrated a strong signal in the esophagus (Figure $2 \mathrm{C}$ ). There was no signal from the anterior part of the esophagus, suggesting an ulcer. PET scanning showed a strong signal in the esophagus (Figure 2D). However, the detailed structure was obscure on the PET scan (Figure 2D). The patient was referred to another hospital for surgery.

\section{Discussion}

The detection rates of stage-T1a, -T1b, -T2, -T3, and -T4 ESC are $0 \%, 42.9 \%, 50 \%, 100 \%$, and 100\%, respectively, using DWIBS. ${ }^{11}$ In our case, DWI clearly demonstrated a high-intensity signal from the proximal to the distal ends 

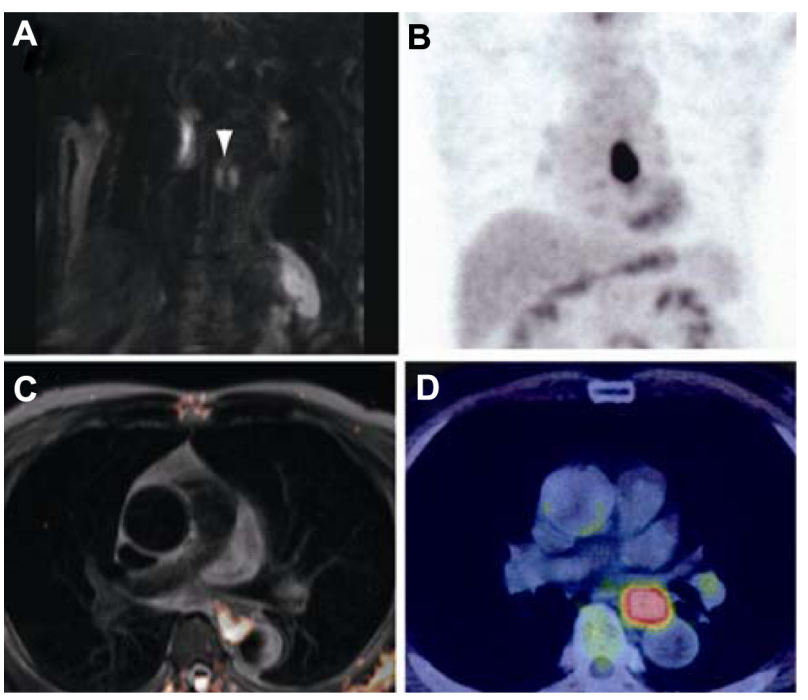

Figure 2 Comparison of diffusion-weighted magnetic resonance imaging with background body signal suppression and ${ }^{18} \mathrm{~F}$-fluorodeoxyglucose positron emission tomography (PET) in esophageal cancer. DWIBS sequence showed esophageal cancer (A). Positron emission tomography (PET) showed a strong signal in the carcinoma. (A) Coronal view of the diffusion-weighted magnetic resonance image; (B) PET scan; (C) sagittal view with DWIBS; (D) sagittal view from PET scan. Note: Arrowhead: lumen of the esophageal cancer.

of the carcinoma. The length of the signal corresponded to the elevated lesion observed during endoscopy. Moreover, the signal extended to the tunica adventitia (Figure 1). CT revealed wall thickening, but the ESC was difficult to detect. These data suggest that DWI is superior to CT for the detection and evaluation of ESC extension because the former highlights the ESC and suppresses unnecessary signals from normal structures such as muscle and bowel tissues. ${ }^{12}$

Detection rates for stage-T1, -T2, -T3, and -T4 ESC are $43 \%, 90 \%, 98 \%$, and $100 \%$, respectively, with FDGPET. ${ }^{13}$ In our case, FDG-PET showed a strong signal, but the structure was not clear. In contrast, DWI clearly showed the ESC and its extension to the tunica adventitia (Figure 1). DWIBS showed the lumen of the ESC (Figure 2). DWIBS also indicated that the signal did not extend to the surrounding tissues. Thus, the findings from our case suggest that DWIBS is superior to FDG-PET for the assessment of ESC extension.

DWI and DWIBS are also useful for the detection of lymph node metastasis. ${ }^{11}$ DWIBS evaluates distant metastasis, such as that to the brain, lung, liver, and bone. ${ }^{14}$ Our case did not have any lymph node or distal metastasis, and this was confirmed with FDG-PET. These findings suggest that DWI and DWIBS are useful for the detection of ESC, and for determining its extent and metastasis.

DWI is also useful for predicting ESC prognosis and response to treatment. It is reported that patients with apparent diffusion coefficient (ADC) values greater than $1.1 \times 10^{-3} \mathrm{~mm}^{2} /$ second had a longer survival period than those with ADC less than $1.1 \times 10^{-3} \mathrm{~mm}^{2} /$ second $(P=0.02$, log-rank test $).{ }^{15}$ They also reported that the former showed better responses to chemoradiation therapy $(P=0.02$, logrank test). The $\mathrm{ADC}$ values decreased with increased amounts of stromal collagen and vascular endothelial growth factor. ${ }^{16}$ They concluded that the ADC values were indicative of the histological background.

\section{Conclusion}

DWI and DWIBS are useful not only for the detection of ESC, but also for determining its extension and for better observing the detailed structure of ESC, compared with CT and PET.

\section{Acknowledgment}

PET was performed in Sannou Hospital Medical Center (Chiba City, Chiba, Japan).

\section{Disclosure}

The authors report no conflicts of interest in this work.

\section{References}

1. Kranzfelder M, Buchler P, Friess H. Surgery within multimodal therapy concepts for esophageal squamous cell carcinoma (ESCC): the MRI approach and review of the literature. Adv Med Sci. 2009; 54(2):158-169.

2. Riddell AM, Hillier J, Brown G, et al. Potential of surface-coil MRI for staging of esophageal cancer. AJR Am J Roentgenol. 2006; 187(5):1280-1287.

3. Didden P, Spaander MC, Wijnhoven BP, Kuipers EJ, Bruno MJ. Improving the quality of pretreatment staging in patients with esophageal carcinoma - a fast track study. Acta Oncol. 2012;51(3):362-367.

4. Umeoka S, Koyama T, Togashi K, et al. Esophageal cancer: evaluation with triple-phase dynamic CT - initial experience. Radiology. 2006;239(3):777-783.

5. Kato H, Miyazaki T, Nakajima M, et al. The incremental effect of positron emission tomography on diagnostic accuracy in the initial staging of esophageal carcinoma. Cancer. 2005;103(1):148-156.

6. Sehy JV, Ackerman JJ, Neil JJ. Apparent diffusion of water, ions, and small molecules in the Xenopus oocyte is consistent with Brownian displacement. Magn Reson Med. 2002;48(1):42-51.

7. Murtz P, Flacke S, Traber F, van den Brink JS, Gieseke J, Schild HH Abdomen: diffusion-weighted MR imaging with pulse-triggered single-shot sequences. Radiology. 2002;224(1):258-264.

8. Bonekamp S, Corona-Villalobos CP, Kamel IR. Oncologic applications of diffusion-weighted MRI in the body. J Magn Reson Imaging. 2012;35(2):257-279.

9. Kwee TC, Takahara T, Ochiai R, Nievelstein RA, Luijten PR. Diffusion-weighted whole-body imaging with background body signal suppression (DWIBS): features and potential applications in oncology. Eur Radiol. 2008;18(9):1937-1952.

10. Komori T, Narabayashi I, Matsumura K, et al. 2-[Fluorine-18]fluoro-2-deoxy-D-glucose positron emission tomography/computed tomography versus whole-body diffusion-weighted MRI for detection of malignant lesions: initial experience. Ann Nucl Med. 2007;21(4):209-215. 
11. Sakurada A, Takahara T, Kwee TC, et al. Diagnostic performance of diffusion-weighted magnetic resonance imaging in esophageal cancer. Eur Radiol. 2009;19(6):1461-1469.

12. Kwee TC, Takahara T, Klomp DW, Luijten PR. Cancer imaging: novel concepts in clinical magnetic resonance imaging. J Intern Med. 2010;268(2):120-132.

13. Kato H, Kuwano H, Nakajima M, et al. Comparison between positron emission tomography and computed tomography in the use of the assessment of esophageal carcinoma. Cancer. 2002;94(4):921-928.

14. Wang N, Zhang M, Sun T, et al. A comparative study: diffusion weighted whole body imaging with background body signal suppression and hybrid Positron Emission Computed Tomography on detecting lesions in oncologic clinics. Eur J Radiol. 2012;81(7):1662-1666.
15. Aoyagi T, Shuto K, Okazumi S, Shimada H, Kazama T, Matsubara H. Apparent diffusion coefficient values measured by diffusion-weighted imaging predict chemoradiotherapeutic effect for advanced esophageal cancer. Dig Surg. 2011;28(4):252-257.

16. Aoyagi T, Shuto K, Okazumi S, et al. Apparent diffusion coefficient correlation with oesophageal tumour stroma and angiogenesis. Eur Radiol. 2012;22(6):1172-1177.

\section{Publish your work in this journal}

The International Medical Case Reports Journal is an international, peer-reviewed open-access journal publishing original case reports from all medical specialties. Previously unpublished medical posters are also accepted relating to any area of clinical or preclinical science. Submissions should not normally exceed 2,000 words or
4 published pages including figures, diagrams and references. The manuscript management system is completely online and includes a very quick and fair peer-review system, which is all easy to use. Visit http://www.dovepress.com/testimonials.php to read real quotes from published authors.

Submit your manuscript here: http://www.dovepress.com/international-medical-case-reports-journal-journal 